\title{
A ENERGIA ELÉTRICA COMO CAMPO DE PESQUISA HISTORIOGRÁFICA NO BRASIL
}

\author{
Sergio Tadeu de Niemeyer Lamarão*
}

\begin{abstract}
A $\mathrm{s}$ inovações técnico-científicas e industriais observadas nas três últimas décadas do século XIX afetaram de forma determinante a esfera da produção, a estrutura social, a vida cotidiana e o imaginário dos homens, desenhando um novo modelo de organização e funcionamento da civilização ocidental. ${ }^{l}$ A chamada sociedade urbano-industrial, circunscrita espacialmente até a virada do século XIX para o século XX à Europa Ocidental e aos Estados Unidos, conquistaria escala planetária no decorrer dos Novecentos, incorporando progressivamente o restante do mundo.

A energia elétrica ${ }^{2}$ desempenhou papel crucial neste processo de modernização. Com efeito, a presença multiforme da eletricidade afetou profundamente o modo de morar, transportar-se, trabalhar, curar-se, divertir-se e estudar de milhões de pessoas. A luz elétrica, o bonde, o trem, o metrô, as unidades de cirurgia e radioterapia hospitalares, os eletromésticos, os aparelhos de refigeração, os computadores, o

* Pesquisador do Centro de Pesquisa e Documentação de História Contemporânea do Brasil

1 A redação deste ítem introdutório foi baseada em Memória da Eletricidade, Panorama do setor de energia elétrica no Brasil, Centro da Memória da Eletricidade no Brasil, Río de Janeiro, 1988 (textos de Lígia Maria Martins Cabral, Paulo Brandi de Barros Cachapuz e Sergio Tadeu de Niemeyer Lamarão) [doravante Panorama do setor elétrico]. pp. $7-9$

2 A importancia da eletricidade reside na combinação de duas características essenciais: a transmissibilidade, faculdade de deslocar a energia no espaço sem grandes perdas; e a flexibilidade, faculdade de se converter, com facilidade e bom rendimento, em outras formas de energia - calor, luz e movimento. Uma corrente elétrica pode produzir, indiferentemente, estas três formas de energía, separadamente ou em conjunto, e o usuário pode passar de uma a outra à vontade. Ele pode também dosar exatamente a quantidade de força motriz desejada e Pode mudá-la se necessário, sem perder tempo com adaptações sem sacrificar o efeito útil ( $c f$. David S. Landes, $L$ Europe technicierme on le Promméthée libéré, Éditions Gallimard, París, 1975, p. 387).
\end{abstract}


cinema, o rádio e a televisão dependem tanto da eletricidade quanto as fábricas, lojas e escritórios que empregam milhões de trabalhadores em todo o mundo.

No último quartel do século XIX, o Brasil viveu um processo de modernização da sua infra-estrutura (transportes, comunicações e serviços públicos urbanos), financiado em grande parte pelo notável crescimento das exportações, sobretudo de café. ${ }^{3}$ Pólo dinâmico da economia, o complexo exportador cafeeiro paulista introduziu a mão-de-obra livre do imigrante europeu num país onde, até a Abolição (1888), as relações escravistas eram dominantes, permitindo o alargamento do mercado interno. Os excedentes aligerados começaram a ser invertidos na indústria no final da década de 1880 . O avanço da urbanização e o conseqüente aumento do mercado de serviços públicos e das atividades industriais no Sudeste ofereceram boas perspectivas para investimentos no campo da energia elétrica, atraindo inclusive capitais estrangeiros.

As primeiras experiências práticas com a eletricidade no Brasil ocorreram no final da década de 1870 e na seguinte ${ }^{4}$ e foram contemporâneas às aplicações iniciais dessa nova modalidade de energia na Europa e nos EUA. A intensificação dessas experiências -particularmente no Rio de Janeiro, capital e principal centro urbano do país-, tornou a eletricidade um agente de indução e de aceleração das mudanças observadas nas práticas sociais e econômicas desde o final do Império e, em especial, a partir do advento da República (1889).

A produção de energia elétrica em larga escala teve lugar na década de 1900, por iniciativa do grupo Light, sediado no Canadá. Em poucos anos, a empresa montou no eixo Rio-São Paulo um importante sistema de geração, transmissão e distribuição de energia elétrica. Em 1900, a São Paulo Light and Power inaugurou uma linha de bondes elétricos e em 1901 a usina hidrelétrica de Parnaíba, para fornecer energia à capital paulista. A Rio de Janeiro Tramway, Light and Power

3 Este ítem foi construido com base em Panorama do setor elétrico. pp. 29-78, e na versão original do verbete "Eletrobrás", de autoria de Paulo Brandi de Barros Caehapuz, constante da segunda edição do Dicionánio HistóricoBiográfico Brasileiro (em elaboração), CPDOC/FGV

4 A primeira aplieação, em earáter permanente, da luz elétrica no Rio de Janeiro e no Brasil oeorreu em fevereiro de 1879 , quando foram iluminadas à eletricidade algumas dependências da estação central da Estrada dc Ferro D. Pedro II (atual Central do Brasil). em substituição aos hicos de gás. Quatro anos depois. foi inaugurada a primeira linha de bondes a tração elétrica no Brasil. em Niterói (RJ), mas a experiéncia durou apenas dois anos. Outra iniciativa ocorrida em 1883 foi a inauguração, em Campos (RJ), do primeiro serviço de iluminação pública municipal do Brasil e da América do Sul. O primeiro emprego do potêncial hidrelétrico para fins industriais ocorreu em 1889 , com a inauguração da usina de Marmelos, no rio Paraibuna. A hidrelétrica foi idealizada por Bernardo Mascarenhas que, após visita à Exposição Universal de 1878, em Paris, resolveu instalar uma fábrica de tecidos em Juiz de Fora (MG) acionada com energia de origem hidráulica, além de dotar a cidade de iluminação elétrica. 
foi constituida em 1905 e três anos depois inaugurou a hidrelétrica de Fontes, com $12000 \mathrm{kw}$ instalados, então uma das maiores do mundo.

O capital privado nacional chegou a desempenhar papel significativo na expansão do parque elétrico brasileiro, através de empresas como a Companhia Brasileira de Energia Elétrica, a Paulista de Força e Luz e a CataguasesLeopoldina. Entretanto, na década de 1920 a Light e a norte-americana Amforp promoveram um intenso processo de concentração e centralização de concessionárias que culminou, no final do decenio, com a quase completa desnacionalização da indústria de energia elétrica brasileira. Paralelamente, a capacidade instalada cresceu de forma continuada, pass ando de $12000 \mathrm{kw}$ em 1900 a 150 mil kw em 1910, 362 mil kw em 1920 e 778 mil kw em 1930.

Se durante a República Velha (1889-1930) o papel do Estado na expansão da indústria de energia elétrica foi circunstancial, ${ }^{5}$ após a Revolução de 1930 a situação foi profundamente alterada. A centralização político-administrativa do país e o fortalecimento da ação do Estado em diferentes planos da vida social, inclusive no econômico, repercutiram, obviamente, nas atividades de energia elétrica. Em 1934. Getúlio Vargas promulgo u o Código de Águas, que estabelecia a competencia exclusiva do governo federal como poder concedente dos aproveitamentos hidrelétricos e previa a fixação de tarifas pelo eusto do serviço. Em 1939, foi criado o Conselho Nacional de Águas e Energia Elétrica com o objetivo de aperfeiçoar a legislação e solucionar as dificuldades que se delineavam na oferta de energia elétrica. A presença estatal na área de geração teve início em 1943, quando o governo do Rio Grande do Sul constituiu uma comissão visando aproveitar o potêncial hidráulico e as reservas carboniferas do estado. Em outubro de 1945, dias antes de sua queda, Vargas eriou a Companhia Hidro Elétrica do São Francisco (CHESF), incumbida da construção da usina de Paulo Monso, no rio São Francisco

Quando Vargas retornou ao poder em 1951, foi decidida a intervenção di reta do Estado na área de eletricidade, caminho encontrado para amenizar o déficit de energia elétrica, sério obstáculo à industrialização no Brasil. Essa intervenção ganhou forma ao longo da década de 50, mediante pesados investimentos na produção de energia elétrica por parte da União e de alguns governos estaduais, incluindo a inauguração de Paulo Monso (1955) e a construção de hidrelétricas no Sudeste -destacando-se a de Fumas, no rio Grande (MG), fundamental para o suprimento dos mercados e centro de gravidade do sistema interligado da região- e de termelétricas a carvão na região Sul.

Outra iniciativa importante foi o projeto de constituição da Eletrobrás, concebida como empresa pública de âmbito nacional, encarregada de realizar estudos

5 Durante a República Velha, os serviços de energia elétrica eram regidos por contratos celebrados diretamente entre as empresas ou fornecedores particulares e os governos estaduais e sobretudo as prefeituras municipais. sem intermediação ou regulamentação federal. 
e projetos, construir e operar usinas e linhas de transmissão e distribuição, bem como de implantar a indústria pesada de material elétrico. Datado de 1954, o projeto enfrentou a oposição das concessionárias estrangeiras, de amplo segmento do empresariado nacional e de dirigentes de empresas estaduais que temiam a centralização do poder na esfera federal, só vindo a ser transformado em lei em 1961, depois da organização do Ministério das Minas e Energia (1960). Apesar de consagrar a solução estatizante, o texto foi sancionado com vetos, notadamente à participação da estatal na fabricação de material elétrico pesado. Instalada em junhio de 1962, a Eletrobrás logo assumiu as características de uma holding, ancorada basicamente na Chesf e em Fumas, empresa responsável pela construção da usina do mesmo nome. Inaugurada em setembro de 1963, a hidrelétrica evitou um colapso no fornceimento de energia às indústrias de São Paulo e do Rio de Janeiro. Em novembro de 1964, sete meses após a implantação do regime militar no país, a Amforp foi comprada por US\$125 milhões e, com isso, o setor público passou a responder por $54 \%$ dos $7400 \mathrm{Mw}$ de potência instalada em 1965 .

A elevação das tarifas e o apoio dos bancos internacionais (BID e BIRO) favoreceram o setor, cuja estrutura administrativa básica consolidou-se em 1969 , cabendo à Eletrobrás a execução da política de energia elétrica da União e ao Departamento Nacional de Águas e Energia Elétrica (DNAEE), criado em 1965, as funções normativas e fiscalizadoras. A holding passou a contar com mais duas empresas subsidiárias regionais, ao lado de Fumas e da Chesf: a Eletrosul (1968) e a Eletronorte (1972).

Em abril de 1973, os governos do Brasil e do Paraguai firmaram acordo para a construção da usina de Itaipu, preven do a instalação no rio Paraná de $12600 \mathrm{Mw}$ de potência, equivalente a $75 \%$ da capacidade de geração nacional em 1973 . O empreendimento ficou a cargo da Itaipu Binacional, constituída em partes iguais pela Eletrobrás e pela estatal paraguaia Adnmistración Nacional de Electricidad No ano seguinte, em meio à crise internacional do petróleo e a fortes pressões inflacionárias internas, foi lançado o II Plano Nacional de Desenvolvimento que, visando afirmar o poder de competição de indústrias altamente intensivas em energia elétrica, preconizava o aproveitamento dos amplos recursos hídricos disponíveis no país. A decisão de construir a usina de Tucuruí, no rio Tocantins, na Amazônia, obedeceu a essa estratégia. Foi também prevista a instalação de centrais nucleares pela Nuclebrás, criada em 1974. Em janeiro de 1979, depois de quase quatro anos de negociações, o governo brasileiro -sem a prévia audiencia do Congresso e sem nenhuma apreciação técnica da parte da Eletrobrás - adquiriu o controle acionário da Light por US\$ 380 milhões, levando a cabo o processo de nacionalização do setor. ${ }^{6}$

6 A transação suscitou críticas em virtude do alto valor da operação e de questões como a proximidade do fim do contrato de concessão no Rio de Janeiro (1990), que incluía a cláusula de reversão gratuita do acervo da companhia a União. Em março de 1981, a Eletropaulo assumiu os serviços da Light em São Paulo. 
A despeito da reversão do ciclo de expansão da economia, o consumo de energia elétrica manteve taxas elevadas de crescimento até 1980, justificando os pesados investimentos em geração e transmissão. A potência instalada cresceu 2,5 vezes entre 1973 e 1982, alcançando $39000 \mathrm{Mw}$, contribuindo para a expansão da indústria de equipamentos eletromecânicos, dominada pelas multinacionais, e de grandes empresas nacionais de construção civil e engenharia de projetos. As tarifas de energia elétrica começaram a ser utilizadas, no final dos anos 70, como instrumento de política antiinflacionária, deixando de garantir às concessionárias a remuneração mínima legal de $10 \%$ ao ano. O setor manteve seu pesado programa de investimentos graças à massiva contratação de empréstimos externos, sobretudo privados, aumentando seu endividamento. Apesar dessas dificuldades terem provocado o atraso das obras, especialmente na área de transmissão, a Eletrobrás garantiu os recursos para empreendimentos do porte de Itaipu e Tucuruí, inaugurados em 1984.

Após a promulgação da nova Constituição (1988), acirraram-se os conflitos, latentes desde o inicio da década, entre interesses estaduais e federais, estes bastante abalados com o fim do Imposto Único sobre Energia Elétrica e a transferência para os estados da arrecadação tributária equivalente com a criação do Imposto sobre Circulação de Mercadorias e Serviços. No começo dos anos 1990, as concessionárias estaduais passaram a atrasar sistematicamente o pagamento da energia suprida pelas empresas federais e por Itaipu, desarticulando o modus operandi financeiro do setor e virtualmente paralisando as obras de geração.

A reorganização do setor obedeceu a uma política mais ampla de redução da presença do Estado na economia e de estímulo à chamada livre competição em atividades monopolizadas por empresas públicas. Em março de 1993, as concessionárias foram autorizadas a elaborar uma proposta tarifária trianual, a ser submetida ao DNAEE, minimizando assim o controle da União sobre os preços da energia elétrica. Em seguida, foi firmado um pacto entre empresas detentoras de instalações de transmissão, baseado no principio do livre acesso a rede de transporte de energia. O Programa Nacional de Desestatização, lançado em maio de 1995, incluía a Eletrobrás e mais a Chesf, Fumas, Eletronorte e Eletrosul, empresas que, no final do ano, detinham $41 \%$ da capacidade instalada do país, estimada em $55500 \mathrm{Mw}$. A Light, também controlada pela holding, foi vendida em 1996 por US\$2.26 bilhões. A estatal francesa Électricité de France foi a responsável pela aquisição da maior parcela das ações $(34 \%))^{7}$ A definição do novo modelo institucional do setor também levava em conta a privatização das concessionárias estaduais.

70 programa de privatização não abrange o segmento da geração termonuclear, monopólio Constitucional da União, a Itaipu Binacional, nem o sistema de transmissão. 
A história da energia elétrica no Brasil permaneceu, até bem pouco tempo, um território praticamente inexplorado, constituindo-se em objeto de reflexão historiográfica mais sistemática apenas a partir da década de 1980. Convém assinalar, porém, a existência de uma extensa literatura produzida nos últimos cem anos por engenheiros, economistas, juristas e empresários que abrange desde a simples crônica sobre a construção de uma usina hidrelétrica até estudos pormenorizados no campo da engenharia, das ciência econômicas e do direito. ${ }^{8}$

A eletricidade foi incorporada ao repertório de temas explorados pela historiografía brasileira ainda na primeira metade da década de 80 , manifestando o interesse da burocracia pública dc participar do movimento, peculiar àqueles anos de transição da ditadura militar para o regime democrático, ${ }^{9}$ de recuperação da memória e preservação do patrimônio históricos. A necessidade de atender à demanda de autoconhecimento do próprio setor de energia elétrica e de responder à indagação de pesquisadores interessados em conheeer o percurso trilhado pela eletricidade no pais, aliada à preocupação em redesenhar o perfil da empresa pública, promovendo uma relação dinâmica entre Estado e sociedade civil, deu lugar as primeiras iniciativas, no interior de algumas das principais concessionárias federais e estaduais, visando a preservação patrimonial e documental e a organização dos acervos.

Em outubro de 1986, a Eletropaulo promoveu, com o apoio da Eletrobrás, o I Seminário Nacional de História e Energia, marco na pesquisa documental e histórica do setor elétrico brasileiro. ${ }^{10}$ Realizado em São Paulo, o evento reuniu historiadores, brasileiros e estrangeiros, técnicos e autoridades e teve por objetivo trazer a público as experiências acumuladas pelas concessionárias ${ }^{11}$ nos anos anteriores, bem como os depoimentos de profissionais e acadêmicos acerea de diversas questões con cementes a um objeto tão vasto e rico.

Assim, ao lado de relatos sobre os procedimentos relativos à preservação do patrimônio documental, iconográfico e arquietônico, a organização de centros de memória e museus de eletricidade, a montagem de programas de história oral ou

8 Desse amplo conjunto, vale destacar, pela seriedade no tratamento das fontes, o trabalho do engenheiro Pedro Carlos da Silva Teles, História da Engenhana no Brasil- Séculos XVI a XIX, 1984, e a sua continuação, Historia da Engenharia no Brasil- Século XX, 1993. Embora. como o título indica, não aborde especificamente a energia elétrica. a obra inclui toda uma parte dedicada à trajetória da indústria de energia elétrica no país.

9 Vale lembrar que em novembro de 1982, antecipando em sete anos o restabelecimento das eleições di retas para presidente da República, os governadores dos estados brasileiros voltaram a ser escolhidos pelo voto popular.

10 A Eletropaulo editou os Anais do seminário em dois volumes. O primeiro, publicado em ) 987, reúne as conferência e comunicações apresentadas com base em textos escritos e encaminhados à coordenação do evento. $O$ segundo, lançado em 1988, transcreve as conferência e comunicações apresentadas oralmente, bem como os relatórios finais das reuniões de trabalho.

11 Além da Fletropaulo e da Eletrobrás, participaram do seminário a Chesf, a Eletronorte e a Eletrosul, na esfera federal, e a Companhia Estadual de Energia Elétrica (CEE E). do Rio Grande do Su), a Companhia Energética de Minas Gerais (CEMIG), a Companhia Energética de São Paulo (CESP) e a Companhia Paulista de Força e Luz (CPFL), na esfera estadual. 
ou ainda as ações desenvolvidas para atender aos impactos sociais e ambientais provocados pela construção de barragens e enchimento de reservatórios (foi esse o caso da Chesf e da Eletronorte, responsáveis, respectivamente, pela construção das usinas de Itaparica e Tucuruí), teve lugar uma ampla discussão sobre temas como alternativas tecnológicas na área de energia elétrica, o lugar da energia elétrica na história das ciência, energia elétrica e vida cotidiana, as relações entre energia e industrialização à luz da business history, entre outros.

No conjunto das empresas do setor elétrico, a Eletropaulo destacou-se não apenas por ter promovido o próprio seminário, como também por ter apresentado o maior e mais variado conjunto de intervenções, evidenciando o seu pioneirismo no tratamento das questões relativas não apenas à preservação documental e patrimonial, mas também às atividades de pesquisa. Em agosto de 1983, a empresa introduziu em sua estrutura organizacional um departarmento -o Departamento de Patrimônio Histórico (DPH)-, voltado especificamente para responder pelo riquíssimo acervo documental-textual, herdado em grande parte da antiga São Paulo Light, que se traduz em cerca de 15 quilômetros de estantes, inluindo manuscritos, cópias datilográficas de cartas, anotações contábeis e fiscais, prontários de trabalhadores e impressos dos mais variados tipos. A esse material -gerado pela própria São Paulo Light e também pelas empresas extintas, compradas ou incorporadas ao seu patrimônio, e que cobre um arco de tempo que se estende de 1899 aos días de hoje-, somam-se cerca de 200 mil imagens fotográficas (referentes à construção de usinas, aos transportes eletrificados, à iluminação pública e à malha urbana de São Paulo e demais municípios da área de concessão), abundante documentação cartográfica (desenhos, mapas, plantas e aerofotogrametrias relativas a projetos de construção de usinas, estações geradoras e transmissoras, linhas de transmissão etc), além de equipamentos e uma valiosa coleção de recortes de jornais com aproximadamente dois mil volumes. Encontrase também disponível material audiovisual, com um número significativo de filmes e muitas horas de depoimentos gravados.

O DPH começou a funcionar plenamente em 1985, quando foi definida sua estrutura básica e constituída a equipe nuclear, de formação multidisciplinar, reunindo historiadores, arquitetos, sociológos, engenheiros, museólogos, arquivistas, bibliotecários, jornalistas e técnicos em editoração. A sua linha de publicações incluía inventários do acervo documental, um Boletim Histórico, de periodicidade bimensal, que noticiava as principais iniciativas do Departamento, e o caderno História \& Energia, publicação de cunho temático que reunia artigos de pesquisadores internos e de fora da instituição. O primeiro número, lançado em maio de 1986, enfocava a chegada da Light na capital paulista. Na área de preservação do patrimônio arquitetônico, priorizou-se o inventário de bens móveis e imóveis com valor histórico-cultural, entre os quais o complexo da hidrelétrica Henry Borden, na serra do Mar, e o prédio Alexandre Mackenzie, sede da empresa, localizado no centro de São Paulo. 
A CESP, maior empresa paulista de energia elétrica e uma das maiores do país, organizou, no início dos anos 80, o Projeto Memória CESP, mais tarde institucionalizado como seção da Divisão de Documentação da Diretoria Administrativa da companhia. Integrada basicamente por historiadores e técnicos em documentação, a equipe iniciou seus trabalhos percorrendo o interior do estado com o objetivo de recolher a documentação relativa às empresas formadoras da CESP. $^{12}$ Foi localizado um vasto e rico material, compreendendo mapas, memorandos, escrituras, orçamentos diversos, contratos e folhas de pagamento, além de 8000 fotografias registrando as diversas etapas da construção de usinas, sobretudo no arquivo da S. A. Central Elétrica de Rio Claro, uma das mais antigas empresas de eletricidade de São Paulo. Um estudo desse arquivo possibilitou a publicação, em1986, do primeiro fascículo da série "História da Energia Elétrica em São Paulo", que viria a ser seguido por mais cinco números. O con tato com antigos empregados da Rio Claro serviu de ponto de partida para o Programa de História Oral da CESP, lanerado em 1985 quando foi iniciada a coleta de depoimentos com aqueles trabalhadores. Essas entrevistas resultaram em 1987 no livro Falam os pioneiros da eletricidade. No ano seguinte, a companhia publicou uma Bibiliografia da história da energia elétrica no Brasil.

Criada pela Eletrobrás no Rio de Janeiro em outubro de 1986, dias antes da realização do I Seminário, o Centro da Memória da Eletricidade no BrasilMemória da Eletricidade, exatamente por estar vinculado à empresa holding, tinha por objetivo buscar a integração entre os esforeros isolados já empreendidos por algumas empresas do setor elétrico, servindo de espaço de troca de experiências e de pólo disseminador dessas práticas e prestando assessoria às iniciativas locais de preservação da memória. Defíniu-se como tarefa prioritária a montagem de um centro de referência, dotado de um banco de dados que permitisse recuperar as informações contidas nos acervos documentais do setor, gerando um importante instrumento para que estudiosos e as próprias empresas conhecessem a localização, o conteúdo e as fontes nccessárias às suas pesquisas. Foi também organizada uma área de comunicação e divulgação, integrada por museólogos e jornalistas, responsável pela edição de um boletim e pela montagem de exposições.

A Memória da Eletricidade contava igualmente em sua estrutura com um setor de pesquisa voltado para a história do fenômeno elétrico ${ }^{13}$ no Brasil, cuja rotina de atividades estava a cargo não apenas de um quadro próprio de historiadores, mas também de pesquisadores e auxiliares contratados externamente. Esse setor ainda apoiava projetos executados por universidades, instituições de pes-

12 Constituida em dezembro de 1966, a CESP originou-se da fusão de 11 empresas estaduais de energia elétrica, cujas áreas de concessão correspondiam a maior parte do território paulista.

13 Desde o inicio, o núcleo de pesquisa da instituição preocupou-se em recuperar a história da energia elétrica num contexto mais amplo, encarando a eletricidade como o resultado de uma trama de interações técnicas e também sociais, políticas e ideológicas. Para tal, manteve ativa interlocução com a Association pour l'histoire de l' électricité en France, onde, vale assinalar, este dominio de investigação também era relativamente recente. 
quisa etc. O primeiro projeto, implementado entre 1987 e 1988 , teve por objeto o estudo da chamada fase pré-operacional da Eletrobrás (1953-1962). Pesquisadores do setor de história oral do Centro de Pesquisa e Documentação de História Contemporánea do Brasil (CPDOC) entrevistaram 19 técnicos do setor de energia elétrica, membros da Assessoria Econômica do segundo governo Vargas e parlamentares da década de 50, constituindo um acervo de 113 horas de fitas gravadas e trasncritas. Encontram-se à disposição do público interessado não apenas este conjunto de entrevistas, como a publicação Programa de história oral da eletricidade-catálogo de depoimentos, editada em $1990{ }^{14}$ Ainda em 1987, a equipe interna da área de pesquisa da Memória da Eletrieidade elaborou $o$ Panorama do setor de energia elétrica no Brasil. Publicado em 1988, o livro representou um esforço de síntese e sistematização da literatura dispersa publicada ao longo do tempo sobre o tema, que incluiu em sua extensa bibliografia não apenas as publicações oficiais (relatórios das concessionárias e da Eletrobrás, boletins e congêneres dos ministérios das Minas e Energia, Agricultura, os censos do Instituto Brasileiro de Geografía e Estatística etc.), como também trabalhos produzidos na academia, sobretudo por economistas. ${ }^{15}$

A partir de 1988, abriu-se o leque de pesquisas desenvolvidas pela Memória da Eletricidade com o concurso de pesquisadores externos, sob a supervisão da equipe interna. Assim, foram implementados projetos sobre uma ampla diversidade temática: a história do Centro de Pesquisa de Energia Elétrica (Cepel); a trajetória da energia elétrica no estado do Rio de Janeiro; o papel da eletricidade no processo de urbanização dos dois maiores centros urbanos do país (São Paulo e Rio de Janeiro); a participação da eletricidade no desenvolvimento industrial do Nordeste brasileiro; a situação da eletrifícação rural no Brasil numa perspectiva histórica; estudo de cunho sociológico sobre $\mathrm{O}$ perfil do eletricitário da Rio Light; o crescimento e a difusão da eletricidade como forera motriz na indústria brasileira; a intervenção dos governos do Rio Gande do Sul, Minas Gerais e Paraná no setor de energia elétrica; o padrão de financiamento recen te do setor de energia elétrica no Brasil. ${ }^{16}$ Internamente, procedeu-se a uma investigação das discussões travadas

14 Duas dessas entrevistas foram aprofundadas e publicadas separadamente: Memórias do desenvolvimento: Lucas Lopes, lançada em 1991, e Octavio Afarcondes Ferraz. um pioneiro da engenharia nacional, 1993.

15 Merece destaque especial a dissertaç̃o de mestrado de José Luiz Lima, Estado e energia no Brasil -das origens à criação da Eletrobrás (1890/1962), 1984. Vale também mencionar as dissertações de mestrado de Hildete Araújo, O setor de energia elétrica e a evolução recente do capitalismo no Brasil, 1979, Márcio Wohlers de Almeida, Estado e energia elétrica em São Paulo-CESP. um estudo de caso (1980); Eduardo Bastos, O desenvolvimento do setor de energia elétrica e mas relações com a indústria de equipamentos elétricos no Brasil. 1981; Denizart do Rosário Almeida, Política tarifária e financiamento do setor de energia elétrica no Brasil. 1983

16 As três últimas pesquisas foram desenvolvidas, respectivamente, pelo historiador Almir Pitta, pela economista Elisa Müller e pelos economistas Júlio Almeida e Pedro Aurélio Cardoso, e integravam o projeto "A energia elétrica e a industrialização brasileira", coordenados pelas historiadoras Maria Bárbara Levy e Eulália Lobo. 
no Congresso Nacional sobre a questão elétrica durante a República Velha e dos debates sobre energia elétrica que tiveram como palco o Clube de Engenharia, no Río de Janeiro.

Esse panorama animador, ${ }^{17}$ desenhado na segunda metade dos anos 80 , foi brusca e drasticamente alterado a partir de 1990, com a posse de Fernando Collor de Melo na presidência da Repúbliea. O redimensionamento do peso do Estado na economia trouxe, entre outras conseqüências, uma sensível redução dos quadros de pessoal das empresas estatais brasileiras.. Consideradas não essenciais pelas direções das concessionárias de energia elétrica, as áreas que se ocupavam da preservação da memória histórica e atividades congêneres foram sensivelmente reduzidas. Essa política de desmonte foi acentuada a partir do início do governo Fernando Henrique Cardoso, em janeiro de 1995, em seu afã privatista.

$\mathrm{Na}$ Eletropaulo e na Cesp, o impacto do corte de pessoal e a perda de espaço junto aos detentores de poder nas empresas traduziram-se pela falta de continuidade nos trabalhos desenvolvidos. Problemas técnico-financeiros afetaram a periodicidade de publicações, como Memória, cujo primeiro número foi lançado em 1988. Depois de vários anos interrompida, a série de cadernos História \& Energia foi retomada em 1995, com um número temático intitulado "Ríos, reservatórios, enchentes." As publicações da Cesp também primam pela periodicidade irregular. É esse o caso da série "História da Energia Elétrica em São Paulo," cujo sexto número foi lançado em 1995 e diz respeito à trajetória de uma empresa que atendia o vale do Paraíba do Sul, e do Boletim Memória CESP, cujo primeiro número foi lançado em dezembro de 1991.

Na Memória da Eletricidade, ao lado da extinção do setor de comunicação e informação, com a demissão sumária de pratieamcnte toda a equipe, a ambiciosa programação da área de pesquisa teve de ser revista. A suspensão ou não renovação dos contratos com os pesquisadores externos e a demissão de um dos quatro historiadores da equipe interna provocaram a interrupção da maioria dos projetos em andamento, que encontravam-se em estágios diferenciados de desenvolvimento.18 Reduzida em cerca de um quarto dos seu s efetivos (dez funcionários, incluindo pesquisadores, diretor e pessoal de apoio), a instituição reduziu o ritmo dos trabalhos a partir de 1992. Recorrendo sobretudo a

17 Em virtude da exigüidade de espaço. não foi possível apresentar as iniciativas tomadas por outras empresas púhlicas de energia elétrica. Porém, fica aqui consignado que a CPFL, a Cemig. a CEEE, a Eletrosul, a Eletronorte Chesf, Fumas, a Companhia Paranaense de Energía Elétrica (COPEL), a Companhia de Eletricidade do Estado da Bahia (COELBA), emprestaram valiosa contribuição para o conhecimento da trajetória da energia elétrica no país.

18 Foram editados os textos finais de apenas três projetos: Debates parlamentares sobre energia elétrica na Primeira República. O processo legislativo (texto de Paulo Brandi de Barros Cachapuz), 1990; História do centro de Pesquisas de Energia Elétrica - CEPEL. 1991, e A CEFJ e a história da energia elétrica no Rio de Janeiro (1993). Os relatórios de pesquisa dos projetos sobre energia elétrica e urbanização no Rio de Janeiro e sobre os debates acerca da energia elétrica no Clube de Engenharia, bem como os ensaios que compunham o projeto " $A$ energia elétrica e a industrialização brasileira", ganharam a form a de "mimeo" 
pesquisadores externos, a área de pesquisa desenvolveu três projetos: o primeiro, relativo à história do Grupo Coordenador para Operação Interligada, o segundo sobre a história de Itaipu Binacional e o terceiro sobre racionamento de energia elétrica. ${ }^{19} \mathrm{Na}$ área de documentação, procedeu-se ao tratamento do material em depósito no $4^{\circ}$ Distrito do Departamento Nacional de Águas e Energia Elétrica no Rio de Janeiro, relativo a empresas adquiridas ou incorporadas, em sua maioria, por empresas maiores, ao longo do processo de desenvolvimento do setor no país. Entre 1994 e 1996, por solicitação de Itaipu Binacional, foi elaborado um guia de referência documentais sobre a história da empresa, que compreendeu 0 referenciamento e a análise de 2640 conjuntos documentais. Outra atividade implementada foi a informatização do acervo documental da biblioteca central da Light Serviços de Eletricidade, que consistiu no tratamento técnico de cerca de 15000 documentos. 